\title{
FATORES DETERMINANTES DE PROATIVIDADE AMBIENTAL EM EMPRESAS CEARENSES: ESTUDO DE CASOS MÚLTIPLOS
}

\author{
Francisco César de Castro Neto \\ Mestrando em Administração e Controladoria pela Universidade Federal do Ceará - UFC \\ cesar.consultor.adm@hotmail.com \\ Jonny Cesar Cavalcante de Oliveira \\ Mestrando em Administração e Controladoria pela Universidade Federal do Ceará - UFC \\ Analista de processos na empresa de planos de saúde Camed. \\ jcesarco@camed.com.br \\ Leonardo Gurgel Pitombeira \\ Mestrando em Administração e Controladoria pela Universidade Federal do Ceará - UFC \\ leogurgel@hotmail.com \\ José Carlos Lázaro da Silva Filho \\ Doutorado em Planejamento Ambiental pela Technische Universität-Berlin, Alemanha \\ Professor da Universidade Federal do Ceará - UFC \\ silvafilhode@yahoo.com.br

\section{Mônica Cavalcante Sá de Abreu} \\ Doutorado em Engenharia de Produção pela Universidade Federal de Santa Catarina - UFSC \\ Professora da Universidade Federal do Ceará - UFC \\ mabreu@ufc.br
}

\section{RESUMO}

O objetivo deste artigo é analisar quais são os fatores determinantes de proatividade ambiental das empresascaso, testando o modelo proposto por González-Benito e González-Benito (2006). Para tal estudo, foram escolhidas três empresas sediadas no Ceará e certificadas com ISO 14001. Partindo-se do pressuposto que tal sistema certificado é sinal de iniciativas de proatividade ambiental, levantou-se os fatores identificados positivamente nas empresas. O resultado desta análise qualitativa de múltiplos casos confirma a diversidade de fatores determinantes na amostra estudada e identifica que, mesmo certificadas com ISO 14001, há uma proatividade limitada em duas empresas, tendo sido percebidas características de reatividade (não proatividade) na outra.

Palavras-chave: Gestão Ambiental; ISO 14001; Proatividade Ambiental; Fatores Determinantes.

\section{DETERMINANT FACTORS OF ENVIRONMENTAL PROACTIVITY IN COMPANIES IN CEARÁ: MULTIPLE STUDY CASES}

\begin{abstract}
The aim of this paper is to analyze what are the determinant factors of environmental proactivity in the company cases, testing the model proposed by González-Benito (2006). For this study, three companies with ISO 14001 in Ceará state were chosen. Assuming that certification would be a signal of some environmental proactivity, factors were positively identified within the companies. The results of this qualitative analysis of multiple cases confirm the diversity of determinant factors in this small sample and identify that, even with ISO 14001 certificate, there is limited proactivity in two of the companies and characteristics of reactivity (not proactivity) in one.
\end{abstract}

Keywords: Environmental Management; ISSO 14001; Environmental Proactivity; Determinant Factors. 


\section{INTRODUÇÃO}

A proatividade ambiental é um conceito de gestão socioambiental que diz respeito a ações voluntárias desenvolvidas por organizações para minimizar o impacto ambiental causado por suas operações. Contudo suas ações vão além das exigências legais (Sanches, 2000).

O modelo desenvolvido pelos espanhóis González-Benito e González-Benito (2006) em uma revisão de literatura aponta uma série de características que viabilizariam a proatividade ambiental em uma organização, em razão das pressões que essas empresas sofrem por comporem determinada função ou desempenharem determinado papel na sociedade. De acordo com o modelo, três categorias reúnem os fatores determinantes para a proatividade de uma organização em relação ao meio ambiente: características das empresas, pressões das partes interessadas e outros fatores externos. Na categoria das características da empresa são encontrados os seguintes determinantes: tamanho, grau de internacionalização, posição na cadeia de valor, atitude gerencial/motivações e atitude estratégica. No tocante ao grupo denominado pressão dos stakeholders aparecem os itens stakeholders internos e externos e stakeholders primários e secundários. Quanto à categoria fatores externos, são citados o setor da indústria e a localização geográfica.

O objetivo principal desse artigo é analisar qualitativamente os indicadores de proatividade ambiental encontrados na literatura, aderentes aos determinantes propostos por González-Benito e González-Benito (2006), em empresas cearenses acreditadas com a certificação ABNT NBR ISO 14001, por meio de um estudo de casos múltiplos. Ao final desse trabalho, pretende-se, adicionalmente, relacionar o comportamento de proatividade e reatividade ambiental com a análise dos indicadores, com o intuito de compreender esse comportamento na literatura basilar do assunto.

Esse trabalho estará organizado do seguinte modo: no referencial teórico, apresenta-se, inicialmente, o modelo de González-Benito e González-Benito (2006); seu contexto particular, referente a conceitos de sustentabilidade e proatividade socioambiental, será a tratado na sessão seguinte, a de número dois. Em seguida, na sessão três, apresenta-se uma breve descrição sobre a certificação ISO 14001, que inclui seu histórico, objetivo e sua importância, tendo como base a família de certificações ISO 14000. Na sessão quatro, apresenta-se o método de pesquisa. Na sessão cinco, constam os resultados já com considerações sobre a aderência do modelo com as características das empresas, com o intuito de evidenciar o objetivo já citado do trabalho, via exposição dos dados pesquisados, abrindo espaço para a discussão dos resultados e as considerações finais do trabalho.

\section{REFERENCIAL TEÓRICO}

Para o desenvolvimento da pesquisa foram utilizados dois arcabouços teóricos, um baseado no modelo proposto por González-Benito e González-Benito (2006) sobre fatores determinantes da proatividade ambiental e outro sobre a ISO 14001, como indício consistente de proatividade ambiental em uma organização.

\subsection{O modelo de González-Benito e González-Benito (2006)}

Com a evolução do entendimento e tratamento das questões ambientais por parte das organizações, é possível asseverar que a responsabilidade empresarial, atualmente, exige o atendimento de demandas bem mais complexas do que em relação ao que era exigido no passado até muito recente (Arora; Cason, 1996). Tal evolução foi datada na literatura como um corte paradigmático da década de 1970, quando se deram as primeiras ações ordenadas de empresas poluidoras com o intuito de reduzir suas externalidades negativas (Maimon, 1994; Donaire, 1994; Souza, 2002; Silva Filho, 2007).

Dado o avanço da pesquisa em gestão socioambiental, o que antes era considerado tãosomente uma obrigação legal, como o pagamento de impostos ou obediência à legislação trabalhista, evoluiu perpassando por alguns modelos de pensamento até ser encarada como uma 
questão de posicionamento organizacional, imagem e até mesmo de atitude estratégica (Souza, 2002; Masullo; Leme, 2005). Apesar da regulação legal ainda ser considerada "um fator decisivo no processo de tomada de decisão na área" (Henriques; Sardosky, 1996, p. 381), ela não pode mais ser considerada como um imperativo isolado.

González-Benito e González-Benito (2006) relatam que as organizações normalmente se posicionam, em relação às questões socioambientais, por meio de um contínuo reatividadeproatividade e que esse posicionamento é resultado de um conjunto de características que podem ser agrupadas basicamente em três categorias: características contingenciais relacionadas à empresa, pressão dos stakeholders e fatores externos (González-Benito; González-Benito, 2006; Silva Filho; Abreu; Soares, 2009).

Essas categorias buscam montar um conjunto de fatores motivadores da proatividade ambiental, entendida como um posicionamento empresarial que transcende aos atos motivados unicamente pelas obrigações legais ou pela visão oportunista de lucros diante de qualquer oportunidade em que ocorram, i.e., falhas no mercado ou no estado.

É importante asseverar que uma organização não necessariamente será ambientalmente proativa apenas pelo fato de apresentar as características apontadas no modelo, todavia esses indicadores, em determinado grau, auxiliam na explicação desse comportamento e estão empiricamente relacionados a esse perfil. Assim, é possível asseverar que há boa possibilidade de encontrar em organizações ambientalmente proativas os, assim denominados, fatores determinantes (González-Benito; González-Benito, 2006).

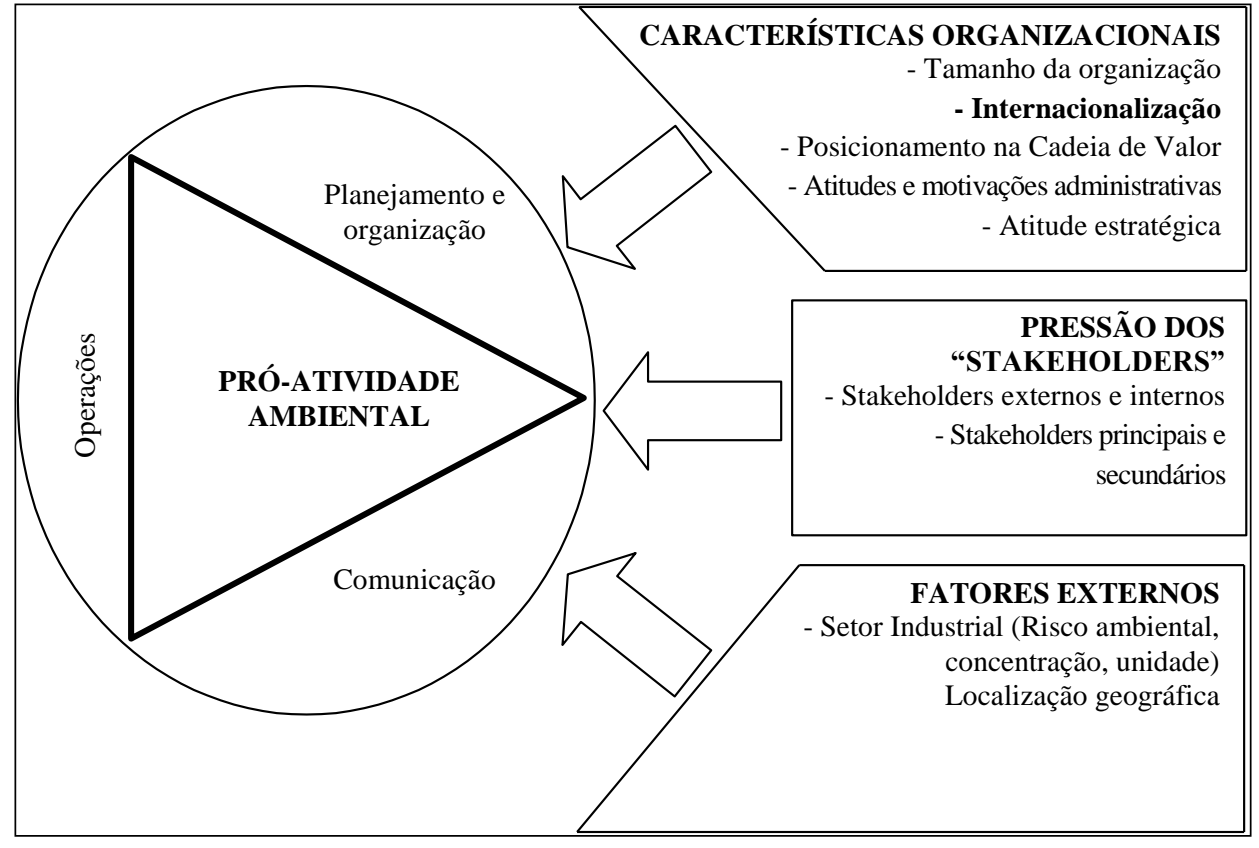

Figura 1: Fatores determinantes de proatividade ambiental

Fonte: Adaptado de González- Benito e González- Benito, 2006, p. 98.

Em uma pesquisa feita para o Instituto de Pesquisa Econômica Aplicada (IPEA), Ferraz e Motta (2002), por meio de um estudo quantitativo, encontraram uma relação positiva entre os fatores pressão da comunidade, tamanho, produção exportada e origem do capital na explicação do nível de investimento ambiental.

A Figura 1 é a representação do modelo de entendimento de proatividade ambiental defendido por González-Benito e González-Benito (2006). Nessa figura, verifica-se que o fenômeno da proatividade ambiental está envolto por um tripé composto por planejamento e organização, operações e comunicação. 
O planejamento e a organização denotam o modelo de planejamento e políticas ambientais, que regulam o arcabouço teórico de valores para a empresa com o objetivo de prepará-la para as ações práticas. As operações são os nichos de mudanças voltadas para a prática ambientalmente sustentável, e estão ligadas, principalmente, a dois eixos: dos processos e dos produtos. A prática comunicacional, por sua vez, encerra o ciclo ao servir como meio de prestação de contas das ações ambientais desenvolvidas pela organização.

Tomando por base o modelo dos fatores determinantes de proatividade ambiental proposto por González-Benito e González-Benito (2006), apresenta-se no Quadro 1 os indicadores adotados na mensuração da qualificação dos fatores e a literatura base utilizada para realizar o procedimento.

\begin{tabular}{|c|c|c|c|}
\hline $\begin{array}{l}\text { Grupo de } \\
\text { fatores }\end{array}$ & Fator determinante & Indicador & Literatura Base \\
\hline & \multirow{4}{*}{ Tamanho } & $\begin{array}{l}\text { Número de } \\
\text { colaboradores }\end{array}$ & González-Benito; González-Benito (2006) \\
\hline & & Acesso aos recursos & Ferraz; Motta (2002); Aragón-Correa (1998) \\
\hline & & Impacto e controle & Aragón-Correa et al (2008) \\
\hline & & Integração institucional & González-Benito; González-Benito (2006) \\
\hline & $\begin{array}{l}\text { Internacionalização } \\
\text { de capital }\end{array}$ & $\begin{array}{c}\text { Existência de } \\
\text { internacionalização de } \\
\text { capital } \\
\end{array}$ & $\begin{array}{c}\text { Mota (2007); Maimon (1994) } \\
\text { Christmann; Taylor (2001) } \\
\text { Buysse; Verbeke (2003) }\end{array}$ \\
\hline & $\begin{array}{c}\begin{array}{c}\text { Posição na cadeia } \\
\text { de valor }\end{array} \\
\end{array}$ & $\begin{array}{c}\text { Posição na Cadeia de } \\
\text { Valor } \\
\end{array}$ & $\begin{array}{c}\text { Doane (2004), Buysse; Verbeke (2003) } \\
\text { González-Benito; González-Benito (2006) }\end{array}$ \\
\hline & Atitude gerencial & $\begin{array}{l}\text { Envolvimento da alta } \\
\text { gerência }\end{array}$ & $\begin{array}{c}\text { Berry; Rondinelli (1998) } \\
\text { Silva Filho; Abreu; Soares (2009) }\end{array}$ \\
\hline & & Auditorias ambientais & $\begin{array}{c}\text { Maimon (1994) } \\
\text { Silva Filho; Abreu; Soares (2009) }\end{array}$ \\
\hline & Atitude estratégica & Marketing ecológico & $\begin{array}{c}\text { Christmann (2000) } \\
\text { McDaniel; Rylander (1993) }\end{array}$ \\
\hline & & $\begin{array}{c}\text { Outras Estratégias } \\
\text { Ligadas à RSE }\end{array}$ & $\begin{array}{c}\text { Carrol (1999) } \\
\text { Darnall et al (2000) } \\
\end{array}$ \\
\hline \multirow{4}{*}{$\begin{array}{l}\text { Pressão dos } \\
\text { stakeholders }\end{array}$} & \multirow{2}{*}{$\begin{array}{c}\text { Stakeholders } \\
\text { internos e externos }\end{array}$} & Stakeholders internos & Calixto (2007); Egri; Pinfield (1998) \\
\hline & & Stakeholders externos & Agle et al (1999);Fortes; Mancini (2005) \\
\hline & \multirow{2}{*}{$\begin{array}{l}\text { Stakeholders } \\
\text { primários e } \\
\text { secundários }\end{array}$} & Stakeholders primários & Hopkins (1997);Barbieri; Cajazeira; (2009) \\
\hline & & $\begin{array}{c}\text { Stakeholders } \\
\text { secundários }\end{array}$ & $\begin{array}{l}\text { González-Benito; González-Benito (2006); } \\
\text { Vivarta; Canela (2006) }\end{array}$ \\
\hline \multirow{4}{*}{$\begin{array}{l}\text { Fatores } \\
\text { externos }\end{array}$} & \multirow{3}{*}{ Setor da indústria } & $\begin{array}{c}\text { Impacto ambiental } \\
\text { inerente ao processo } \\
\text { produtivo }\end{array}$ & $\begin{array}{l}\text { Masullo; Lemme (2005b) } \\
\text { Tachizawa (2005) }\end{array}$ \\
\hline & & Legislação ambiental & Miranda; Samudio; Dourado (1997) \\
\hline & & $\begin{array}{l}\text { Exigências ambientais } \\
\text { das partes interessadas }\end{array}$ & $\begin{array}{l}\text { Abreu; Rados; Figueiredo Jr. (2004). } \\
\text { Weaver; Trevino; Cochran (1999) }\end{array}$ \\
\hline & $\begin{array}{c}\text { Localização } \\
\text { geográfica }\end{array}$ & Localização geográfica & $\begin{array}{c}\text { Barbieri (2007) } \\
\text { González-Benito;González-Benito (2006); }\end{array}$ \\
\hline
\end{tabular}

Quadro 1: Quadro de indicadores

Fonte: Elaborado pelos autores.

Ainda no contexto do modelo, o construto de proatividade ambiental recebe influência, em forma de intensidade e percepção, dos grupos de fatores determinantes (característica da empresa, pressão dos stakeholders e fatores externos).

\subsection{Sistemas ambientais certificados pela ISO 14001}

A International Organization for Standardization, conhecida como ISO, regula desde 1947, data da sua criação, a padronização internacional de bens e serviços por meio da integração das instituições nacionais, com o mesmo fim em todo o mundo. Entre outras famílias de normatizações da instituição, a "família de normas" ISO 14000 se preocupa especialmente com as questões de 
caráter ambiental, sendo normas internacionais de "gerenciamento" ambiental (Seiffert, 2007; ABNT, 2004)

A norma ISO 14001 se preocupa, mais especificamente, com a formulação e operação de sistemas de gestão ambiental como se fosse um programa de melhoria contínua. Os requisitos da norma englobam a política ambiental, o planejamento, a implementação, as operações, a verificação e a análise pela administração (ABNT, 2004).

A política ambiental da empresa é composta por seu conjunto de intenções, perspectivas e compromissos com as partes interessadas. Para Barbieri (2007, p. 170), "a política ambiental estabelece os níveis de responsabilidade e desempenho ambiental requeridos pela organização". Sanches (2000) explicita que a política ambiental, para não ser falaciosa, não pode ser apenas formal, mas deve ser transportada do plano estratégico para o cotidiano. Barbieri (2007) também cita diversos elementos que devem compor a política ambiental, tais como as crenças da organização, sua coordenação com outras políticas, suas condições específicas e sua melhoria contínua.

O planejamento, de acordo com essa visão cíclica, deve ser coerente e estabelecido a partir da política ambiental. De acordo com a NBR ISO 14001-2004 (ABNT, 2004), o planejamento deve se preocupar com a identificação dos aspectos ambientais, dos requisitos legais e dos objetivos, metas e programas.

Aspectos ambientais são "as atividades, produtos ou serviços de uma organização que podem interagir com o meio ambiente" (Barbieri, 2007, p. 172). Os requisitos legais compreendem toda a seara de regulação em que a empresa está inserida. Nesse contexto, os objetivos, as metas e os programas devem ser a tradução, quantificável e mensurável, dos indicadores traçados na política ambiental.

A implementação trabalha com diversas subfases. A primeira compreende os recursos, as funções, a responsabilidade e as autoridades. Em seguida, tem-se a competência, o treinamento e a conscientização; comunicação; controle operacional e de documentos; e a preparação e resposta às emergências (ABNT, 2004).

A fase seguinte diz respeito à verificação, e compreende as subfases de monitoramento e medição, avaliação do atendimento a requisitos legais, não-conformidade, ação corretiva e preventiva; controle de registros e auditoria interna.

Finalmente, na fase de análise pela administração, o sistema de gestão é avaliado quanto à sua efetividade, aos resultados trazidos e buscam-se implementações que satisfaçam à necessidade de melhoria contínua.

A certificação pela ISO14001, comparativamente, é um bom indicador de proatividade ambiental por parte das organizações, no entanto a diversidade de empresas que implementaram tal sistema certificado indica uma provável diversidade de fatores motivadores para essa "proatividade" (Henriques; Sardosky, 1996). Nesse contexto, com base nos estudos levantados, os autores determinaram sua proposição básica de pesquisa, a proatividade ambiental tem diferentes fatores que a provocam sendo possível identificá-los em diferentes intensidades.

\section{MÉTODO DE PESQUISA}

Diante desse problema de pesquisa, optou-se por desenvolver uma pesquisa qualitativa (Richardson, 2007, p. 79). Trata-se de um estudo exploratório, que "permite ao investigador aumentar sua experiência em torno de determinado problema" (Trivinos, 1987, p. 109) que se utiliza, na construção do referencial teórico, das estratégias de pesquisa bibliográfica, procurando explicar e discutir um assunto, tema ou problema com base em referências publicadas (Martins; Teóphilo, 2007). Também é utilizada a pesquisa documental, que na visão de Godoy (1995, p. 21) "é o exame de materiais de natureza diversa que ainda não receberam um tratamento analítico ou que podem ser reexaminados buscando-se novas interpretações". Como forma de integrar o conhecimento do caso, pesquisou-se sites, relatórios administrativos e contábeis das empresas. No 
desenvolvimento da pesquisa, adotou-se o método de estudo de casos múltiplos (Yin, 1994) no intuito de relacionar as práticas de gestão ambiental em diferentes organizações, comparando semelhanças entre elas e destacando suas diferenças. Quanto às técnicas, fez-se uso de formulários. Os formulários são, segundo Marconi e Lakatos (2007, p. 111), "roteiros de perguntas enunciadas pelo entrevistador e preenchidas por ele com as respostas do pesquisado".

\subsection{Desenvolvimento da pesquisa}

Essa pesquisa foi realizada com uma amostra não probabilística motivada pelo fator da acreditação pela certificação ambiental ISO 14001. Dessa forma, assumiu-se pesquisar o modelo utilizado pelo grupo de empresas cearenses que obtiveram êxito no processo de aquisição dessa certificação, apoiado na prerrogativa de que essas, por travarem contato com exigências de acreditação ambiental, ofereceriam mais possibilidades de apresentar indicadores de proatividade ambiental (Henriques; Sardosky, 1996). O grupo pequeno (múltiplos casos) foi escolhido em um Estado sem tradição de proatividade ambiental (vide poucas empresas com ISO 14001), por meio da análise de empresas de diferentes setores industriais.

A relação foi colhida no sítio eletrônico do Instituto Brasileiro de Metrologia (INMETRO), órgão responsável pelo controle da padronização e normatização no Brasil. A lista cita 14 (catorze) empresas, sendo 3 (três) de um mesmo grupo empresarial, totalizando assim onze grupos empresariais distintos. Dos onze, foram tentados contato com oito grupos, dos quais apenas 4 (quatro) se mostraram abertos e disponíveis para realizar uma entrevista. Entretanto, 1 (um) grupo teve problemas de agenda e não foi possível conceder inteiramente a entrevista, restando 3 (três) grupos para análise.

Os primeiros contatos foram estabelecidos por telefone e email com os responsáveis pelos sistemas de gestão ambiental e da qualidade das organizações, informando os propósitos da pesquisa, sua natureza e objetivos. Em seguida, foram enviadas cartas formais com o objetivo de pedir autorização à diretoria ou equivalentes para realizar a pesquisa. Uma vez autorizada, foram marcadas os encontros nos escritórios das empresas pesquisadas. As entrevistas foram semiestruturadas e uma cópia ficava com o(s) entrevistado(s). Todas as entrevistas tiveram suas respostas anotadas como apontamentos e transcritos após seu encerramento por dois dos pesquisadores.

Os relatórios de pesquisa foram confeccionados no mesmo dia da entrevista para não ser deixados para trás detalhes significativos e informações relevantes. A ideia primeira era a de enviar possíveis dúvidas ou entendimentos parciais por email para os pesquisados, porém, em nenhum dos casos essa ação foi necessária.

\section{RESULTADOS}

A análise e descrição dos múltiplos casos foram realizadas uma a uma, numerando as empresas de 1 a 3. No Quadro 2, constam as principais características demográficas dessas organizações.

\begin{tabular}{|c|c|l|c|c|}
\hline Empresas & Setor de Atividade & \multicolumn{1}{|c|}{ Sede } & Fundação & Data ISO 14001 \\
\hline Empresa 1 & Têxtil & Maracanaú & 1946 & 2000 \\
\hline Empresa 2 & Petroquímico & Fortaleza & 1966 & 2001 \\
\hline Empresa 3 & Metal-mecânico & Maracanaú & 1855 & 2008 \\
\hline
\end{tabular}

Quadro 2: Empresas pesquisadas.

Fonte: Dados da Pesquisa

\subsection{Características da Empresa 1}

A Empresa 1 é a maior empresa têxtil da América Latina com 40 anos de existência e 8 mil funcionários. Possui 8 (oito) unidades, distribuídas em Natal/RN (uma unidade), Maracanaú/CE 
(duas unidades), Pacajus/CE (uma unidade), 2 (duas) unidades administrativas em São Paulo/SP (um depósito e um escritório), 1 (uma) unidade em Americana/SP e 1 (uma) unidade no Equador. Conta ainda com escritórios comerciais na Argentina e Europa.

A organização conta com a certificação ISO 9001 desde 1998 (exceto as unidades de São Paulo, Americana e Equador), o que serviu de embasamento para a obtenção da certificação ISO 14001 em 2000 (exceto as unidades de São Paulo e Equador). Foi necessário um ano e meio de preparação para a ABNT NBR ISO 14001 ISO 14001, cuja renovação acontece a cada 3 (três) anos. Interessante observar que determinados produtos da companhia como o índigo e o brim possuem certificações de qualidade própria, com avaliação anual realizada em um laboratório suíço responsável pela requalificação do produto.

O principal fator desencadeador da busca pela certificação ABNT NBR ISO 14001 foi a necessidade de conquistar o mercado europeu que tem sistemas de gestão ambiental como um dos pré-requisitos para a aceitação do produto. De acordo com os entrevistados, "a Europa não aceita mais produtos do gênero sem um SGA e selo verde".

Além disso, já havia uma estrutura básica para a certificação, visto que já contavam com a ISO 9001. Outrossim, instituições de crédito como Banco do Nordeste (BNB), Banco Nacional de Desenvolvimento Econômico e Social (BNDES), Banco Interamericano de Desenvolvimento (BID) e Banco do Brasil (BB) costumam levar em conta a adoção de SGA para concessão de financiamento.

O setor responsável pela gestão ambiental e pela ISO 14001 na empresa é o de qualidade, Total Quality Control (TQC). Essa área também é a responsável pelos treinamentos relacionados ao meio ambiente para os colaboradores e pela gestão das auditorias realizadas no âmbito ambiental.

Adicionalmente, o TQC regula o acompanhamento dos sistemas de licenciamento e documentação necessários para atender às regulações da ISO 14000 que, muitas vezes, se antecedem às leis nacionais. Por outro lado, o órgão também se empenha na busca de clientes e fornecedores que atendam ao perfil desejado pela empresa, no que diz respeito à responsabilidade ambiental.

O TQC está hierarquicamente ligado à Diretoria Industrial e a equipe é composta por duas pessoas, responsáveis por todo o grupo, e mais duas pessoas em cada unidade da empresa. Para dar o apoio técnico e jurídico ao TQC, foi contratada uma empresa de consultoria de legislação que sinaliza sempre que surgem novas regulações no setor ambiental para que a Empresa 1 possa se adequar devidamente aos quesitos legais.

Os pesquisados citaram a dificuldade de realizar o benchmarking para a implantação do SGA, em razão do pioneirismo da iniciativa. A Empresa 1 foi a primeira indústria a obter a ISO 14001 no Estado do Ceará. Adicionalmente, foram mencionadas dificuldades quanto à venda de resíduos para empresas que empreguem o devido tratamento, que apresentem disponibilidade de fornecedores de produtos químicos dentro das especificações e questões relacionadas à disponibilidade de treinamentos para os colaboradores.

Também foram relatadas algumas conquistas na seara ambiental por parte do grupo como, por exemplo, o fato de que em 2009 a Empresa 1 conseguiu que o SENAC autorizasse a queimar estopas e trapos sujos de óleo e graxa (4,5 t/mês) das operações no Nordeste, que é aproveitada como combustível, substituindo a casca de castanha de caju, o gás natural e a madeira. Outro ponto levantado foi a redução de geração de $\mathrm{CO} 2$ (gás carbônico) de transporte por não se enviar o material a ser incinerado até a cidade de Sobral, em torno de $250 \mathrm{Km}$ de distância.

Entre ações de fortalecimento da redução da poluição se destacam a avaliação da escala colorimétrica da fumaça de todos os veículos com carga química perigosa que entram na Empresa 1. Adicionalmente são avaliadas as condições do caminhão, do extintor de incêndio e se o motorista possui treinamento para lidar com situações de emergência relacionadas à carga.

Os programas e prêmios, relacionados a seguir, foram obtidos pelos projetos de responsabilidade social empresarial, desenvolvidos pela Empresa 1: 
- Programa de Educação Ambiental - PEA. A cada seis meses cada unidade deve treinar pelo menos $80 \%$ dos seus funcionários em algum tema relacionado ao meio ambiente;

- Projeto de Reuso foi iniciado em 2001-2002, com o aproveitamento de 70 a $75 \%$ da água utilizada pelas unidades de Maracanaú, algo equivalente ao consumo do município de Horizonte;

- Semana do Meio Ambiente com o envolvimento da comunidade local;

- Reconhecimento do Selo Procel na redução do consumo de energia;

- Prêmio Top of Quality em 2003 na categoria indústria têxtil;

- Prêmio Delmiro Gouveia em 2002, 2004 e 2005, ficando entre os sete primeiros colocados em todas as outras edições.

\subsubsection{Pressão dos stakeholders}

Segundo os entrevistados, existe muito mais uma pressão hoje da Empresa 1 sobre seus fornecedores e clientes do que um movimento oposto, embora não se possa esquecer que a pressão dos clientes europeus foi fator motivador para adoção de sistema de gestão ambiental e, consequentemente, da acreditação da ABNT NBR ISO 14001.

Conforme regras da certificação, os fornecedores da empresa devem seguir determinados parâmetros para que a Empresa 1 possa se tornar compradora.

Quanto à pressão dos órgãos regulamentadores, a certificação ISO 14001 mostra que a Empresa 1 cumpre a legislação ambiental brasileira (SEMAM, SEMACE, COGER, IBAMA, SRH, Ministério Público). A empresa, segundo os entrevistados, chegou a instruir alguns órgãos reguladores sobre questões legais ligadas ao meio ambiente.

A sociedade em geral não representa uma forte fonte de pressão, pelo contrário, a empresa representa um modelo local de preocupação e regulação ambiental, recebendo constantes visitas de instituições de ensino com o propósito de conhecer seu portfólio de ações ambientais.

\subsubsection{Fatores externos}

A empresa faz parte do segmento têxtil de indústrias, classificado em estudo do BNDES de 2003 como de risco ambiental leve (BERGAMINI JR, 2003). Sua localização geográfica no Ceará aponta para um estado brasileiro sem histórico de rígida fiscalização ambiental. Pelos dados da entrevista, é perceptível o fato de a regulação própria da acreditação ISO 14001 ser mais contundente e incisiva do que a dos órgãos governamentais reguladores e fiscalizadores.

\subsection{Características da Empresa 2}

A Empresa 2 é uma unidade do grupo Petrobrás, responsável pelo refino do petróleo e produção de óleos lubrificantes básicos no Estado do Ceará. Dessa forma, sua política ambiental é fortemente influenciada pela gigante estatal. Esta, prevendo sua expansão no mercado internacional e com intuito de evitar acidentes, buscou desde a década de 1980 sua adequação ambiental.

Uma das ações desenvolvidas nesse processo de aproximação ao paradigma ambiental foi a formação de comissões de meio ambiente em cada unidade de negócio da empresa para tratamento dessas questões. De forma mais ampla, foram incluídas também tanto no planejamento corporativo quanto nas metas corporativas após o vazamento histórico de 1,5 milhões de litros do oleoduto RioSantos em novembro de 1983.

Dois grandes acidentes envolvendo a Petrobras em 2000 aceleraram o processo de certificação. Em 18 de janeiro de 2000, ocorreu um derramamento de 1,3 milhões de litros de óleo na baía de Guanabara com o rompimento de um duto da Refinaria de Duque de Caxias (REDUC), no Rio de Janeiro. Em julho do mesmo ano, quatro milhões de litros foram despejados nos rios 
Barigui e Iguaçu, após rompimento de um duto da Refinaria Presidente Getúlio Vargas - Araucária (REPAR) em outra unidade da empresa, no Paraná.

A busca pela certificação já era meta da companhia, mas foi feito grande aporte de recurso financeiro para antecipação das metas de certificação ambiental após esses dois acidentes.

Localmente, a Empresa 2 foi certificada pela ISO 14001 em 2001 - quando as certificações eram ainda específicas para cada refinaria. Por meio do projeto Sistema Integrado de Gestão (SIG), o objetivo da empresa era certificar todas as unidades. Em 2008, todas as unidades de refino da Petrobras foram certificadas na OHSAS 18000, ISO 14.001 e ISO 9001. As certificações são multissite, certificação válida para todas as unidades da empresa.

Hierarquicamente, a gestão do SGA se dá em níveis. Há uma gerência corporativa no nível estratégico, outra em cada regional e uma coordenação em cada unidade, sendo esta a estrutura da unidade pesquisada.

Especificamente na unidade estudada, a principal dificuldade apontada no processo de acreditação foi a mudança de cultura organizacional, que envolveu a divulgação dos projetos por parte da área de comunicação e a implementação de projetos de integração pela área de RH.

Por outro lado, o desenvolvimento do sistema de gestão ambiental promoveu uma sensível melhoria nos processos, pois contou com o envolvimento da alta gerência e a capacitação da força de trabalho. De acordo com os entrevistados, a adequação às normas ambientais levou à redução de acidentes, diminuição de custos pelo aumento de produtividade das unidades e ganhos financeiros pela redução de multas impostas à Petrobras.

Outro ponto positivo destacado na pesquisa foi a preparação para a expansão para mercado internacional pela corporação.

Quanto à promoção da responsabilidade social empresarial, a Empresa 2 desenvolve diversas ações implementadas no nível corporativo. Por ano, são investidos mais de R \$ 500 milhões em aproximadamente 2,3 mil projetos sociais, ambientais, culturais e esportivos. Existem incentivos para projetos locais em cada unidade de acordo com suas particularidades.

$\mathrm{Na}$ unidade pesquisada, os projetos são implementados pela coordenação de gestão em conjunto com a área de comunicação. Entre os quais, destacam-se:

- treinamentos constantes para situações emergenciais, com plano de fuga, uma vez que a Empresa 2 está localizada próxima a uma comunidade bastante habitada (Morro Santa Terezinha);

- patrocínio do Projeto Artesanato, que incentiva a inclusão social por meio da confecção e venda de peças artesanais feitas pela comunidade local.

- alfabetização de jovens e adultos da vizinhança;

- aulas de dança patrocinada pela empresa;

- disponibilização de biblioteca para a comunidade local;

- doação de material escolar.

\subsubsection{Pressão dos stakeholders}

As pressões sofridas pela Empresa 2 por seus stakeholders, citadas na entrevista, remontam mais a um perfil informal do que formal. Segundo os respondentes, "diversos clientes consideram relevantes as certificações ambientais" e os colaboradores, por tratar-se de uma atividade com periculosidade, consideram importante que a empresa mantenha políticas que evitem acidentes.

Uma vez que as ações da empresa são negociadas em bolsas internacionais, as questões de imagem tornam-se importantes, visto que são afetadas por regulações internacionais.

Foi citada a existência de pressão governamental pelo fato de a Empresa 2 ter como acionista controlador a Petrobras, uma empresa de capital misto. A licença de operação é fornecida pela Secretária Municipal de Meio Ambiente (Seman), que exige a formulação de um Plano de Gerenciamento de Resíduos Sólidos (PGRS). O restante da legislação ambiental a ser atendida é

Revista de Gestão Social e Ambiental - RGSA, São Paulo, v. 5, n. 1, p. 48-65, jan./abr., 2011. 
determinada pela Secretaria de Meio Ambiente do Estado do Ceará (Semace), dado que a Seman não legisla em grande parte das empresas de grande porte.

\subsubsection{Fatores externos}

A Empresa 2 faz parte do segmento petroquímico de indústrias, classificado, em estudo do BNDES de 2003, como de risco ambiental grande (BERGAMINI JR, 2003). Sua localização geográfica aponta para um estado brasileiro sem histórico de rígida físcalização ambiental. A entrevista, todavia, sugere pressão dos órgãos de fiscalização pelo tipo de indústria e pelo fato de a empresa ter como acionista controlador a Petrobrás.

\subsection{Características da Empresa 3}

A Empresa 3 é uma empresa cearense que industrializa componentes automotivos (tambores de freio, discos de freios, cubos de roda, entre outros) e os comercializa principalmente para as montadoras de automóveis, Mercedes Benz, General Motors. Sua atuação remonta ao ano de 1855 quando iniciou suas operações como uma empresa familiar. Desde 1996, está localizada no Distrito Industrial do Município de Maracanaú, um pólo regional de indústrias na região metropolitana da capital cearense. Essa empresa possui três certificações, ISO 9001 (Sistemas de Qualidade), QS (Qualidade padrão para Cadeia Automotiva) e ISO 14001 (Sistema Ambiental), tais acreditações são geridas conjuntamente pelo setor SGI (Sistema de Gestão Integrado) composto por uma equipe de 10 pessoas.

Essa equipe é liderada pela representante da Diretoria e reforçada por mais sete representantes de áreas da empresa (RH, Produção, Segurança, etc.) que intermediam as ações e decisões do comitê da qual fazem parte em seus departamentos específicos. Ainda compõem a equipe dois auxiliares, sendo um no Ceará, trabalhando diretamente com a gestora, e outro no escritório de São Paulo, onde a empresa também atua.

A certificação ISO 14001 foi implantada entre agosto e dezembro de 2008, sendo o órgão atual de acreditação o Bureau Veritas Certification (BVC). Segundo os respondentes, a rapidez com que o processo decorreu se deu em razão da expertise advinda com os processos de certificação anteriores (9001 e QS) como também de uma cultura de atenção às normas ambientais que a companhia já possuía antes da sua implantação, por força do seu ramo de atividade.

A empresa está inserida no segmento de grande porte (para o padrão regional), possuindo hoje mais de 350 funcionários e com uma receita bruta na ordem de $\mathrm{R} \$ 132.233 .121,00$, de acordo com seu balanço patrimonial publicado de 2008. Metade de seu capital é nacional e a outra estrangeira, uma vez que a empresa tem participação acionária de um grupo espanhol, um conglomerado europeu atuante no setor automobilístico e de biocombustíveis presente também na China, México, República Tcheca e Portugal.

Na visão dos pesquisados, um importante entrave no processo de implantação e manutenção da certificação tem sido o volume e a complexidade da legislação ambiental que rege o setor. No caso da Empresa 3, foi contratado um serviço de monitoramento e de aporte de informação sobre a legislação pertinente que auxilia no controle legal do processo e mune o comitê gestor de dados sobre mudanças legais, dando origem ao surgimento de novas leis ou mesmo extinguindo as normas vigentes.

Os principais benefícios citados foram a conscientização dos colaboradores quanto à importância da preservação dos recursos utilizados pela empresa. Em termos de processo produtivo, a manutenção dos níveis ótimos de utilização de energia e ferro-gusa, que é a principal matériaprima da empresa utilizada na confecção de peças, foram indicadores citados como pontos de sucesso da implantação. A "perda de cargas" (processamento de ferro feito de maneira incorreta que implica perda de material) é um dos tópicos trabalhados nas políticas e nos indicadores de redução 
de energia e matéria-prima, um impacto considerável em uma empresa cujo volume produtivo mensal chega a seis mil toneladas.

Os principais resíduos gerados no processo de produção da empresa são a escória e a areia de fundição e o tratamento é dado de acordo com as características de periculosidade e inércia do material.

O fator internacionalização do capital, no caso da Empresa 3, foi primordial para a busca da certificação ISO 14001, uma vez que houve a exigência do grupo adquirente nesse sentido.

A empresa, em sua principal operação que é a venda de componentes automotivos para montadoras de automóveis, está distante do consumidor final na cadeia de valor. As operações secundárias, que incluem a venda de peças de reposição, estão mais próximas do cliente final, mas, segundo os entrevistados, não há influência dos consumidores finais na política ambiental. As atitudes e motivações gerenciais percebidas dizem respeito aos aspectos formais do processo de certificação, apoio e acompanhamento da alta gerência, traduzidos em disponibilização e conferência de ações em mídia eletrônica entre Direção e SGI como também via reuniões mensais de análise e avaliação do gerenciamento do sistema. Como indicativo de atitude estratégica, foi apontada a participação do projeto de certificação ambiental nos documentos de planejamento estratégico da empresa desde 2008.

\subsubsection{Pressão dos stakeholders}

De acordo com a pesquisa, as principais pressões de caráter ambiental sofridas se deram por parte dos clientes e, principalmente, acionistas. Os clientes da Empresa 3, mesmo antes da divisão acionária, já cobravam da empresa o atendimento a obrigações legais como documentação ambiental atualizada mas, como já foi mencionado, foi exigência do grupo espanhol a acreditação na ISO 14001.

Segundo os respondentes, não são percebidas pressões por parte de colaboradores, grupos ativistas, governo, sindicatos ou associações comerciais. Quanto aos fornecedores, é o inverso que ocorre, a empresa faz exigências quanto à responsabilidade ambiental e atendimento legal, e recomenda certificação ambiental. Em termos de concorrentes, foi citada a existência de uma pressão indireta, decorrente de uma necessidade crescente de organização de sistemas ambientais como fator de sobrevivência no mercado e aceitação por parte dos clientes e acionistas.

\subsubsection{Fatores externos}

A empresa faz parte do segmento metal-mecânico de indústrias, classificado em estudo do BNDES de 2003 como de risco ambiental grande (Bergamini Jr, 2003). Sua localização geográfica aponta para um estado brasileiro sem histórico de rígida fiscalização ambiental. A entrevista destacou o descontentamento com as instituições reguladoras de caráter governamental. Segundo a percepção dos pesquisados, na esfera municipal, a secretaria responsável ainda não dispõe de porte e know-how para tratar com empresas grandes, como a Empresa 3, e o órgão estadual responsável apresenta morosidade mesmo em operações cotidianas como renovações de licença ambiental.

\section{ANÁLISE E DISCUSSÃO DOS RESULTADOS}

Na reunião e análise dos dados, procedeu-se a criação do Quadro 3, em que são resumidos os indicadores para cada caso e classificados como positivo ou negativo, de acordo com o que foi levantado na pesquisa.

\begin{tabular}{|c|c|c|c|c|c|}
\hline $\begin{array}{c}\text { Grupo de } \\
\text { fatores }\end{array}$ & Fator determinante & Indicador & Empresa 1 & Empresa 2 & Empresa 3 \\
\hline \multirow{2}{*}{$\begin{array}{c}\text { Características } \\
\text { da empresa }\end{array}$} & \multirow{2}{*}{ Tamanho } & Número de colaboradores & Positivo & Positivo & Positivo \\
\cline { 3 - 6 } & & Acesso aos recursos & Positivo & Positivo & Positivo \\
\cline { 3 - 6 } & & Impacto e controle & Positivo & Negativo & Positivo \\
\hline
\end{tabular}

Revista de Gestão Social e Ambiental - RGSA, São Paulo, v. 5, n. 1, p. 48-65, jan./abr., 2011. 


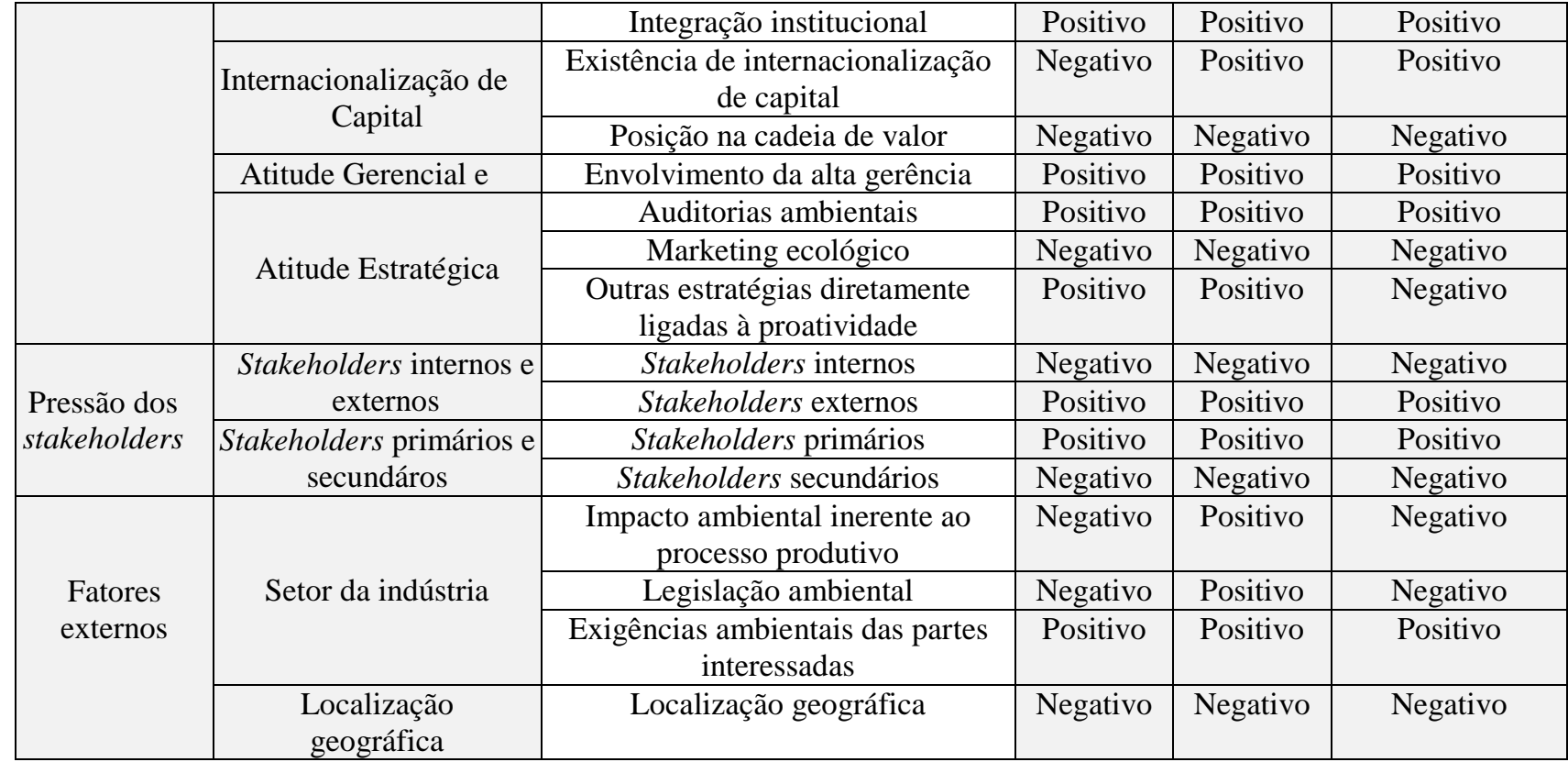

Quadro 3: Análise dos indicadores

Fonte: dados da pesquisa

Por positivo, entende-se que o indicador pôde ser identificado satisfatoriamente na empresa pesquisada e é suficientemente relevante para o fator determinante. Ao contrário, por negativo classifica-se o indicador que, por sua inexistência, existência insatisfatória, irregular ou comprometida, concorre para tornar irrelevante o fator determinante.

A análise dos indicadores representativos dos determinantes de proatividade ambiental encerra as seguintes questões a respeito do entendimento contextualizado de organizações, o que possibilitou alocá-las no contínuo reatividade-proatividade.

No caso da Empresa 1, dos 18 indicadores, tem-se 10 direcionamentos positivos e oito negativos. A organização tem desempenhado um movimento no sentido da proatividade ambiental, embora de maneira muito gradual. É interessante perceber que a empresa reconhece seu papel na dinâmica da sociedade e do meio ambiente, refletindo-o em seu discurso.

A Empresa 2, por sua vez, apresenta também um direcionamento de proatividade com explicação possível pelo comportamento do grupo Petrobras, do qual faz parte. Apresentou 12 indicadores com direcionamentos positivos e seis negativos. Pôde ser sentido um entendimento de necessidade de cuidado ambiental como responsabilidade, papel e função social.

A Empresa 3 apresentou uma divisão de direcionamento de indicadores exatamente igual à Empresa 1, dez positivos e oito negativos. Por outro lado, esse caso parece apontar para um caso de reatividade ambiental. Em que pese ser o caso onde a acreditação é a mais recente, pareceu ser a organização que está mais voltada para sua estabilização ambiental, ao atendimento à regulação e ao cumprimento de metas para sustentar sua certificação.

É importante asseverar que nenhuma das três apresenta comportamento proativo estabelecido, mas sim um entendimento menos raso de consciência ambiental e esforço de sustentação e ampliação de sistemas de gestão ambiental.

O porte e envergadura das empresas lhes garantem capacidade de investimento e experiência em implantação e sustentação de sistemas de gestão, como é o caso do ambiental. De outra forma, a integração é verificada nos modelos analisados pela unificação dos sistemas de gestão da qualidade e ambiental e o binômio impacto/controle se revelou presente, em razão das diretrizes da certificação ambiental. Sem dúvida, o fator determinante "tamanho" exerce forte influência nas três, apontando confirmação de González-Benito e González-Benito (2006), Ferraz e Motta (2002) e Aragón-Correa (1998). 
O capital da Empresa 1 não é internacionalizado, fator que pode implicar gradualidade do movimento de proatividade, pelo fato de esta não participar de um contexto de pressão internacional por acionistas e reguladores. Esse fator, "internacionalização do capital”, é influente na empresa 3 (aquisição por grupo estrangeiro) e na empresa 2 (ações em bolsas internacionais). Nessas, sua influência é bastante nítida. Para a empresa 3, inclusive, pode ser considerada condição sine qua non, confirmação e exemplo de Masullo e Lemme (2005a). Aqui também se confirmou Maimon (1994), Christmann e Taylor (2001) e Buysse e Verbeke (2003).

O fator "posição na cadeia" também não parece exercer influência nos casos das Empresas 1 e 3. Uma causa aparente é o reconhecimento pelo consumidor final ser embotado pelos demais participantes na cadeia que separa a produtora do usuário final. Dados que corroboram essa falta de influência da posição na cadeia é a ausência de sentimento de pressão por parte dos entrevistados com relação aos consumidores finais dos produtos, ou seja, da sociedade organizada em geral ou mesmo por parte de grupos ativistas.

Ao contrário, a Empresa 2, mesmo não trabalhando diretamente com clientes finais, por fazer parte de um grupo nacional conhecido e mais regulado trava contato mais direto com esse tipo de questão. Pelo estudo, portanto, não foi possível confirmar Doane (2004), González-Benito e González-Benito (2006) ou Buysse e Verbeke (2003).

Em termos de "atitude gerencial", as três empresas apresentam um isomorfismo pelo fato de nas três haver envolvimento da alta gerência. Esse isomorfismo é explicado por meio da característica da acreditação ambiental que, per se, exige a presença desse indicador. Há, portanto, confirmação de Berry e Rondinelli (1998) e de Silva Filho, Abreu e Soares (2009).

No tocante à "atitude estratégica", também é encontrado um modelo isomórfico para a presença de auditorias ambientais, pelos mesmos motivos explicitados acima. Aqui, confirma-se Maimon (1994) e Silva Filho, Abreu e Soares (2009). Nenhuma das empresas apresentou um projeto concreto de marketing ecológico, como forma de posicionamento estratégico, mas a Empresa 1 e a Empresa 2 comunicaram suas ações de Responsabilidade Social Empresarial. Essa constatação sugere a necessidade de testar um relacionamento positivo entre proatividade, marketing ecológico e comunicação de RSE. Em resumo, não se confirmam Christmann (2000) nem McDaniel e Rylander (1993), mas Carrol (1999) e Darnall et al (2000).

Mais isomorfismo pode ser constatado quando se analisa os determinantes relativos à "pressão" exercida por "stakeholders". Com intensidades um tanto variáveis, parece haver um direcionamento positivo de influência de stakeholders primários e externos em detrimento dos secundários e internos, que apresentam padrões muito baixos de influência (informais). Assim, puderam ser confirmados Agle, Mitchell e Sonnenfeld (1999), Fortes e Mancini (2005) Hopkins (1997) e Barbieri e Cajazeira (2009), mas não Calixto (2007), Egri e Pinfield (1998), GonzálezBenito e González-Benito (2006) ou Vivarta e Canela (2006).

No grupo de fatores externos, o determinante "setor da indústria" traz indicadores contrastantes. O impacto ambiental do negócio é percebido apenas na Empresa 2 (ramo petroquímico), confirmando, pois Masullo e Lemme (2005b) e Tachizawa (2005). O indicador legislação ambiental, por conseguinte, do mesmo modo é percebido, isto é, confirma Miranda, Samudio e Dourado (1997). As empresas 1 e 3 não confirmam esse indicador.

As exigências ambientais das partes interessadas com sua influência positiva são isomórficas nos três casos. Aqui, a acreditação não é causa, mas consequência de leis de mercado que impulsionaram as três organizações a se acreditarem. São confirmados, assim, Abreu, Rados e Figueiredo Jr. (2004) e Weaver, Trevino e Cochran (1999).

A "localização geográfica" é comum aos três e, claramente, não exerce influência. Por isso não foi possível confirmar esse indicador de Barbieri (2007) e González-Benito e González-Benito (2006) para os casos pesquisados. 
Por fim fica claro, que mesmo entre três empresas de um mesmo estado, com algo praticamente incomum na região, a certificação ISO14001, há diferentes fatores que ajudam a explicar a proatividade ambiental, mas não a determinam.

\section{CONSIDERAÇÕES FINAIS}

Dada a evolução do entendimento e tratamento das questões ambientais por parte das organizações é possível asseverar que a responsabilidade empresarial hoje enfrenta demandas bem mais complexas do que há alguns anos (ARORA; CASON, 1996).

Na perspectiva de González-Benito e González-Benito (2005), três são os argumentos que embasam as práticas ambientalmente proativas em uma empresa: a crescente conscientização ambiental da sociedade e a respectiva temeridade da organização com respeito às questões de imagem e reputação; o efeito de otimização operacional advinda das práticas de eficiência ambiental e; por fim, os questionamentos éticos com que se deparam os proprietários, gestores e acionistas das companhias a que estão relacionados.

Nesse contexto, o presente artigo teve como objetivo analisar qualitativamente os indicadores de proatividade ambiental encontrados na literatura, aderentes aos determinantes propostos por González-Benito e González-Benito (2006), em empresas cearenses acreditadas com a certificação ABNT NBR ISO 14001, por meio de um estudo de casos múltiplos.

A Empresa 1 tem desempenhado um movimento no sentido da proatividade ambiental, embora seja por meio de um processo ainda moroso. Pode-se inferir que a empresa compreende seu espaço na responsabilidade perante a sociedade e ao meio ambiente, o que pode ser percebido em seu discurso e ações.

Por sua vez, a Empresa 2, também aparenta ser orientada para a proatividade, para o que contribui ser subsidiária de uma das maiores companhias do país e com relevante risco ambiental. Foi possível perceber um discurso e tomada de ação com foco na necessidade de cuidado ambiental como responsabilidade, papel e função social.

A Empresa 3 demonstrou uma padrão mais voltado para a reatividade ambiental. Como trata-se do caso em que a acreditação ambiental é a mais recente, a organização demonstra ser aquela que está mais voltada para sua estabilização ambiental, ao atendimento à regulação e ao cumprimento de metas para sustentar sua certificação.

O estudo, intrinsecamente exploratório, abre espaço para a discussão sobre a possível diversidade de fatores da proatividade ambiental empresarial, contrapondo propostas que busca identificar um único fator com o determinante do desenvolvimento da gestão ambiental, de certa forma se consolida uma abordagem da gestão ambiental como contingencial as organizações.

Como limitações da pesquisa os autores entendem que o acesso a apenas três empresas é um fator limitante, mas contornável pelo caráter exploratório da pesquisa. Por outro lado, a escolha de empresas já certificadas com ISO14001 acabou gerando um viés positivo o que impediria qualquer generalização, mas também pode ter gerado algumas similaridades indiretas nos fatores analisados.

Recomenda-se, para a seara teórica, a discussão do tema com assuntos correlatos tais como pressão ambiental e responsabilidade ambiental com o intuito de resgatar pontes teóricas que auxiliem no amadurecimento do tópico e reconstruam liames teóricos quando do entrelaçamento das literaturas contíguas citadas.

No campo empírico, há espaço para pesquisas com diferentes abordagens, tanto qualitativas como quantitativas com a ampliação da amostra. O uso de modelos de análise e previsão econométricos dentro de um survey amplo podem ser úteis na compreensão da existência de fatores determinantes em empresas comprovadamente proativas. Já, frente a limitações prováveis de um estudo amplo, estudos qualitativos seriam importantes na análise do desenvolvimento de modelos de proatividade ambiental em diferentes organizações, sempre quando possível isolando uma das seguintes variáveis: o setor, a localização geográfica ou o tamanho. 
Partindo deste artigo e da base aberta desta pesquisa uma outra questão a ser trabalhada é o conceito de proatividade ambiental empresarial e seu desenvolvimento junto com novos padrões e exigências sociais às empresas

\section{REFERÊNCIAS}

ABNT - Associação Brasileira de Normas Técnicas. NBR Iso 14001(2004) - Sistemas de Gestão Ambiental: requisitos com orientação para uso. Rio de Janeiro: ABNT.

Abreu, M. C. S., Rados, G. J. V., Figueiredo Jr, H.S.(jul./dez. 2004). As pressões ambientais da estrutura da indústria. RAE-eletrônica, 3 (2).

Agle, B. R., Mitchell, R. K., Sonnenfeld, J.A. (1999) What matters to CEO's? An investigation of stakeholders attributes and saliences, corporate performance and CEO values. Academy of Management Journal, 42 (5), p. 507-525.

Aragón-Correa, J. A. et al.( January 2008) Environmental strategy and performance in small firms: a resource-based perspective. Journal of Environmental Management, 86 (1) p.88-103.

Aragón-Correa, J. A (1998) Strategic proactivity and firm approach to the natural environment. Academy of Management Journal, 41 (5), p. 556-567.

Arora, S.; Cason, T.(nov.1996) Why do firms volunteer to exceed environmental regulations? Understanding Participation in EPA's 33/50 Program. Land Economics. 72, p. 413-32.

Barbieri, J. C. (2007). Gestão ambiental empresarial. São Paulo: Saraiva.

Barbieri, J.C., Cajazeira, J.E.R.(2009) Responsabilidade social empresarial e empresa sustentável: da teoria à prática. São Paulo: Saraiva.

Bergamini Junior, S.(dez.2003) Classificação de risco ambiental: o modelo construído no BNDES. Revista do BNDES. Rio de Janeiro, 10 (20), p. 197-228.

Berry, M.A, Rondinelli, D.A. (1998) Proactivity corportate environmental management: a new industrial revolution. Academy of Management Executive. v. 12. n. 2, p. 38-50, 1998.

Buysse, K.;Verbeke, A. (2003). Proactive environmental strategies: a stakeholder management perspective. Strategic Management Journal. v. 24, n. 5, p. 453-470.

Calixto, L.(2007). Responsabilidade Social Corporativa no Brasil: um estudo longitudinal. In: ENANPAD, 31. Anais Eletrônicos... Rio de Janeiro.

Carrol, A. B. (September, 1999) Corporate social responsability: evolution of a definitional construct. Business \& Society, 38 (3), 268-295.

Christmann, P. (2000) Effects of "best practices" on environmental management on cost advantage: the role of complementary assets. Academy of Management Journal. 43 (4), p. 663.

Christmann, P., Taylor, G.(2001) Globalization and the environment: determinants of firm selfregulation in China. Journal of International Business Studies, 32 (3), p. 439-458. 
Darnall, N., Galagher D. R., Andrews, R. L., Amaral D. (Spring 2000) Environmental management systems: opportunities for environmental and business strategy. Environmental Quality Management, 9 (3), p. 1-9.

Doane, D. (mar./abr. 2004) Beyond corporate social responsability: minnows, mammoths and market. Futures. 37 (2-3), p. 215-229.

Donaire, D. (mar./abr.1994) Considerações sobre a influência da variável ambiental na empresa. Revista de Administração de Empresas. São Paulo, 34 (2), p. 68-77.

Egri, C. P., Pinfield, L.T. (1998) Ecologia e meio ambiente. In: Clegg, S. T.; Nord, W. R.; Hardy, C. Handbook de estudos organizacionais. São Paulo: Atlas.

Fortes, F. Z.; Mancini, S. (2005) Gestão estratégica para o desenvolvimento sustentável e participação de stakeholders. In: ENGEMA. 8. Anais Eletrônicos... Rio de Janeiro.

Godoy, A.S. (mai/jun, 1995). Pesquisa qualitativa: tipos fundamentais. Revista de Administração de Empresas. São Paulo, 35 (3), p. 20-29.

González-Benito, J.; González-Benito, O. Perfiles de Proatividad Medioambiental: evidencias en empresas industrials españolas. Universia Business Review: actualidad econômica, p. 92-101, janmar, 2005.

González-Benito, J., González-Benito, O. A review of determinant factors of environment proactivity. Business Strategy and the Environment, 15, p. 87-102, 2006.

Henriques, I., Sardosky, P. (1996) The determinant of an environmental responsive firms: an empirical approach. Journal of Environmental Economics and Management, 30, 381-395.

Hopkins, M. (1997) Defining indicators to assess socially responsible enterprises. Futures. 29(7), pp. 581403.

Maimon, D.( jul./ago. 1994) Eco-estratégia nas empresas brasileiras: realidade ou discurso. $R A E$ Ambiental. 34(4), p. 119-130.

Marconi, M.A., Lakatos, E. M.(2007). Metodologia do trabalho científico. 7. ed., São Paulo: Atlas.

Martins, G.A.de, Theóphilo, C.R. Metodologia da investigação científica para ciências sociais aplicadas. São Paulo: Atlas, 2007.

Masullo, D. G., Leme, C. F. (2005a) Nível de internacionalização como condicionante da divulgação de informações sobre responsabilidade ambiental nas grandes empresas brasileiras de capital aberto. In: EnAnpad, 29. Anais Eletrônicos. Brasília.

Masullo, D. G., Lemme, C. F.( Nov, 2005b) Relação entre responsabilidade ambiental e setor de atuação. In: ENGEMA. 8. Anais Eletrônicos... Rio de Janeiro: EAESP/FGV.

Mcdaniel, S. W., Rylander, D. H.(1993) Strategic green marketing. Journal of Consumer Marketing, 10 (3), p.4-10. 
Miranda, N. G. M., Samudio, E. M. M., Dourado, F. F. M. A (jan./mar. 1997). A estratégia de operação e a variável ambiental. Revista de Administração. 32(1), p. 58-67, São Paulo.

Mota, R. B.(2007) Decisões estratégicas no processo de internacionalização de empresas: "forma de entrada" e "seleção de mercado". In: Encontro de Estudos em Estratégia. 3 Anais Eletrônicos... São Paulo.

Richardson, R.J. (2007) Pesquisa social: métodos e técnicas. 3 ed. Ver. Amp., São Paulo: Atlas.

Sanches, C.S. (jan./mar. 2000) Gestão ambiental proativa. RAE - Revista de Administração de Empresas. São Paulo, 40 (1).

Seiffert, M.E.B. (2007) ISO 14000 Sistemas de gestão ambietal. (3ª Ed.) São Paulo: Atlas.

Silva Filho, J.C.L., Abreu, M. C. S., Soares, F. A. (2009) Fatores determinantes para práticas ambientais organizacionais: uma revisão e um estudo múltiplo de casos em um setor industrial. In: SIMPOI. 2009. Anais Eletrônicos... São Paulo: FGV-EAESP.

Silva-Filho, J. C. L. (mai./ago., 2007) Socioambiental: O perigo da diluição de dois conceitos, Gestão Ambiental e Responsabilidade Social Empresarial. Revista Gestão.Org, 5 (2).

Souza, R. S. (nov-dez 2002) Evolução e condicionantes da gestão ambiental nas empresas. REAdEdição Especial 30, 8(6).

Tachizawa, T. (2005) Gestão ambiental e responsabilidade social corporativa. São Paulo, Atlas. (3 $3^{\text {a }}$ Ed. Revista e Ampliada).

Trivinos, A.N. S.(1987) Introdução à pesquisa em ciências sociais. São Paulo: Atlas.

Vivarta, V., Canela, G.( mar./ 2006) Corporate social responsibility in Brazil: the role of the press as watchdog. The Journal of Corporate Citizenship. 9 (3), p. 230-254.

Weaver, G. R., Trevino, L. K. (1999). Cochran, P. L. Integrated and decoupled corporate social performance: management commitment, esternal pressures and corporate ethics practices. Academy of Management Journal. 42(5), p. 539-552.

Yin, R. K. (1994) Case Study Research. Design and Methods. Thousand Oaks: Sage.

Data do recebimento do artigo: 02/09/2010

Data do aceite de publicação: 23/03/2011

Revista de Gestão Social e Ambiental - RGSA, São Paulo, v. 5, n. 1, p. 48-65, jan./abr., 2011. 